\title{
Bolha de Preços no Mercado Acionário: Uma Análise do Setor da Construção Civil no Brasil
}

\section{Prices Bubble in Stock Market: An Analysis of the Civil Construction Sector in Brazil}

\author{
Bruno Vinícius Ramos Fernandes* \\ Ana Júlia Eiras da Silveira** \\ Paulo Roberto Barbosa Lustosa***
}

Resumo: O desempenho dos diversos setores da economia ao longo do tempo está sujeito a uma série de interferências e influências que determinam a dinâmica de sua evolução, passando por momentos de grande euforia, num extremo, a outros de profunda estagnação e recessão. Sabendo-se que o mercado de ações funciona como um verdadeiro termômetro destas mudanças, o presente trabalho teve por objetivo investigar indícios que pudessem caracterizar a ocorrência de um processo de formação de bolha de preços no setor imobiliário. Para tanto, o estudo partiu da análise de cotações históricas das ações e seus respectivos dividendos de empresas da construção civil do Brasil presentes na BMËF Bovespa. As análises estatísticas dos valores estudados mostraram que as cotações, na grande maioria dos casos, apresentam um alto nível de dispersão e que os retornos esperados destas ações se distribuem em um intervalo percentual nada uniforme. Do ponto de vista econométrico, o estudo empregou testes de cointegração para análise de séries históricas das variáveis, concluindo que mais da metade da amostra de dados não possui cointegração, revelando a possibilidade de presença de um componente especulativo. Tendo em vista as disparidades dos dados, o trabalho postula, desta maneira, que o setor de construção civil brasileiro possui componente de bolha nos preços de suas ações.

Palavras-chave: Bolha de preços. Teste de Cointegração. Valor Fundamental da Ação.

Professor assistente do Departamento de Ciências Contábeis e Atuariais da Universidade de Brasília (UnB) e doutorando do Programa Multiinstitucional e Inter-Regional de Pós-graduação em Ciências Contábeis da UnB/UFPB/UFRN. E-mail: brunoramos@unb.br

** Graduada em Ciências Contábeis pela Universidade de Brasília (UnB). E-mail: anajulia.es@gmail.com

*** Professor titular do Departamento de Ciências Contábeis e Atuariais da Universidade de Brasília (UnB) e do Programa Multiinstitucional e Inter-Regional de Pós-graduação em Ciências Contábeis da UnB/UFPB/UFRN. E-mail: lustosa@unb.br 
Abstract: The performance of various sectors of the economy over time is subject to a number of interferences and influences that determine the dynamics of their evolution, through moments of great euphoria at one extreme, the other a deep recession and stagnation. Knowing that the stock market functions as a true indicator of these changes, this study aimed to investigate evidence that could characterize the occurrence of a process of formation of prices bubble in stock market. For this, the study was the analysis of historical prices of stocks and their dividends from the civil construction companies present in Brazil's BMEF Bovespa. Statistical analysis showed that the values studied quotations, in most cases, present a high level of dispersion and expected returns of these stocks are distributed in a uniform percentage range nothing. From the econometric point of view, the study employed co-integration tests for time series analysis of variables, concluding that more than half of the sample data has no co-integration, the possibility of revealing the presence of a speculative component. Given the disparity of data, the paper contends, in this way, the Brazilian civil construction sector has component bubble in their stock prices.

Keywords: Bubble Prices. Co-integration Test. Fundamental Value of Stock.

JEL Classification: G01; G14.

\section{1 lntrodução}

O sistema capitalista, desde seu princípio, registra diversos quadros antagônicos: dos grandes surtos de euforia e otimismo, baseados nos altos retornos e lucros das atividades, até períodos de depressões agudas e estagnação econômica.

No mercado acionário a história não poderia ser diferente. Funcionando como um termômetro dos fatos econômicos, apresenta-se sensível tanto às instabilidades quanto aos momentos de prosperidade da economia mundial. Os valores dos títulos nele negociados, por sua vez, refletem não somente o desempenho de suas respectivas empresas, mas também os abalos positivos e negativos do ambiente no qual está inserido.

Movimentos especulativos já abalaram diversas economias e bolsas de valores após o estouro de bolhas, tendo como principais motivações uma busca irrefreável por lucros ou o otimismo irracional. Longe de ser um fenômeno recente, há registros de países que passaram por sérias crises no século XVII e XVIII, como o caso das tulipas na Holanda e a bolha dos mares do sul envolvendo a Inglaterra, que serão vistos mais adiante.

De uma forma geral as bolhas ocorrem quase sempre da mesma maneira: diante de um quadro otimista investidores aplicam recursos em títulos ou ativos que prometem retornos expressivos. Com a popularidade dos lucros, novos in- 
vestidores são atraídos. O otimismo exacerbado se alastra e o fluxo de capital se intensifica cada vez mais. No entanto, ganhos e preços não crescem infinitamente, chegando ao momento de estagnação. Diante da perspectiva de redução dos lucros e na tentativa de evitar futuras perdas, os investidores decidem livrar-se dos títulos ou ativos o mais rápido possível. Como geralmente a decisão não ocorre de forma individual, o que se observa é um aumento brusco nas vendas, ocasionando uma queda vertiginosa dos preços em função do aumento da oferta. Neste instante a euforia é substituída pelo pânico. Investidores veem seus recursos subitamente desvalorizados e o quadro econômico entra em colapso.

Uma vez que situações como estas ocorrem com certa frequência e numa tentativa de lançar novas luzes sobre a discussão acerca deste fenômeno, o presente artigo tem por objetivo analisar o comportamento dos preços das ações das empresas de construção civil do Brasil. Procura, dessa forma, evidências de fatores que possam caracterizar a formação de uma possível bolha de preços no setor, tendo em vista que o aumento expressivo dos valores dos imóveis em importantes capitais brasileiras como Brasília, São Paulo e Rio de Janeiro, nos últimos anos chamou a atenção para o desenvolvimento de pesquisa correlacionada.

Para alcançar as conclusões o estudo toma por base o comportamento de séries históricas das ações e de seus respectivos dividendos estimados das empresas de construção civil, listadas na bolsa de valores de São Paulo, BMËF Bovespa.

$\mathrm{O}$ trabalho segue em mais quatro seções além desta introdução. Um breve referencial teórico a respeito do histórico da ocorrência de bolhas, bolhas de preços, hipótese de mercado eficiente, valor fundamental da ação, dividendos e modelo de Gordon. Em seguida a metodologia de pesquisa realizada, depois são apresentadas as análises de resultados e discussão frente ao arcabouço proporcionado pela literatura utilizada e, finalmente, as considerações finais.

\section{Referencial Teórico}

O referencial teórico esta dividido em seis partes que se relacionam entre si. O primeiro tópico trata de uma análise histórica da ocorrência de bolhas seguida da teoria sobre bolhas em ativos, assim os dois tópicos abordam o tema principal do estudo. Os tópicos seguintes estão relacionados com a construção metodológica, e são utilizados para dar embasamento as análises dos resultados e conclusões. A hipótese de mercado eficiente (HME) é descrita com o intuito de subsidiar o conhecimento sobre precificação de ações, pois o processo de formação de bolhas está diretamente ligado a falta de racionalidade na atribuição de valor aos ativos. Em seguida, o tópico valor fundamental da ação, abre espaço para os dois temas seguintes, dividendos e modelo de Gordon, que são base de valor para uma ação, tratando da diferenciação entre valor fundamental e valor especulativo. 


\subsection{Análise Histórica}

Dentre os casos históricos de ocorrência de bolhas especulativas mais referenciadas por estudiosos do tema, quatro episódios merecem destaque: a comercialização de tulipas na Holanda, no século XVII; a especulação das ações da South Sea Company na Inglaterra, no século XVIII; o crash de 1929 nos Estados Unidos; e, mais recentemente, a bolha imobiliária que culminou na crise financeira americana em 2008.

O caso das tulipas holandesas teve início no século XVI, quando por volta de 1554 , as primeiras mudas começaram a ser cultivadas na Holanda. A popularidade das flores cresceu rapidamente, e devido a sua raridade e beleza se transformou em artigo de luxo e símbolo de status, tornando-se artigo indispensável das classes mais altas da sociedade (SORNETTE, 2003).

Com o aquecimento da demanda o crescimento desenfreado dos preços foi inevitável. A irracionalidade tomou conta das transações e tulipas passaram a ser trocadas por animais, casas, terras e até negociadas em bolsas de valores das cidades ricas da Holanda. Eram negociados também bulbos de tulipas que tinham acabado de ser plantadas, conhecidos como "contratos futuros de tulipas" (transações conhecidas como windhandel - negócio de vento). O crescimento dos preços não cessou até 1636 (MARTINS, 2009).

Porém, em fevereiro de 1637, sem motivo aparente, a suspeita de que a procura pelas flores não duraria tomou conta do mercado. Os proprietários começaram a vendê-las rapidamente, acarretando uma queda brusca nos preços. $\mathrm{O}$ pânico se alastrou e a chamada "Bolha das Tulipas" estourou, causando prejuízos enormes a grande parte da população.

Outro episódio ocorreu no século XVIII, mas desta vez na Inglaterra. À companhia marítima South Sea Company foi concedido o monopólio do comércio dos portos dos mares do sul, em troca a empresa assumiria uma parte da dívida inglesa decorrente da Guerra de Sucessão Espanhola. Quando a Inglaterra e a Espanha oficialmente entraram em guerra de novo, em 1718, as perspectivas imediatas de qualquer benefício nos negócios com a América do Sul foram anuladas (SORNETTE, 2003).

Visto que os anos recentes de 1700 refletiam um bom momento para as finanças internacionais, em 1719, os diretores da South Sea Company decidiram assumir toda a dívida pública do governo inglês. A companhia começou a empurrar os preços de suas ações por meios artificiais e isto, somado com as histórias de prosperidade no comércio, criou uma impressão de que os preços das ações da South Sea Company cresceriam cada vez mais, atraindo inúmeros investidores (SORNETTE, 2003).

No entanto, altas de preços e retornos não são infinitas, chegando um momento de estagnação, desencadeando posteriormente uma venda numerosa das 
ações, resultando em uma queda violenta nos preços. Os acontecimentos passaram para a história como a "Bolha dos Mares do Sul".

No início do século XX, nos Estados Unidos, uma nova onda especulativa deu espaço para mais uma crise financeira, desta vez de repercussão mundial. Na década de 20, o grande volume de inovações tecnológicas provocou um aumento da produção em larga escala no país e, com a Europa devastada após a primeira guerra mundial, os países aliados tornaram-se os principais destinos das exportações americanas. As fábricas de bens de consumo duráveis e semiduráveis produziam a todo vapor.

Em conjunto com o grande volume de produção e aumento das atividades, o mercado acionário crescia e valorizava, os preços das ações das empresas dispararam, criando um cenário de especulação e euforia nas bolsas de valores, principalmente na bolsa de Nova York. Entretanto, posteriormente, a Europa foi se recuperando e importando cada vez menos dos Estados Unidos, havendo uma drástica redução na demanda. Diante de estoques lotados, reduções e cortes inteiros de grandes encomendas, as empresas começaram a apresentar resultados ruins e, em consequência, o mercado financeiro se abalou e o pânico se instaurou na principal bolsa de valores americana. Os preços das ações despencaram, prejuízos enormes se alastraram e a crise estourou no mundo.

Mazzucchelli (2008, p. 4) comenta que a crise de 1929 "[...] foi precedida pela fragilidade da regulação e pelo relaxamento na percepção dos riscos, o que redundou em uma febre especulativa de consequências desastrosas.". O mesmo autor afirma que "a inevitável proliferação de operações financeiras de lastro duvidoso, alavancadas pela expansão desmesurada do crédito" foi um traço característico desta crise.

O registro mais recente de ocorrência de bolha de preços aconteceu também nos Estados Unidos, começando em meados de 2007, estourando abruptamente em agosto de 2008, levando à falência inúmeras empresas e instituições financeiras, fazendo ecoar novamente muitos dos temores vividos durante a crise de 29.

Para Bresser-Pereira (2008, p. 195) esta foi "[...] uma profunda crise de confiança decorrente de uma cadeia de empréstimos originalmente imobiliários baseados em devedores insolventes que, ao levar os agentes econômicos a preferirem a liquidez e, assim, cobrarem em vez de renovarem seus créditos."

No início deste século, a grande procura por imóveis e a rápida expansão do setor imobiliário levaram a um superaquecimento do mercado americano. Com o aumento de preços, bancos de investimento e agências imobiliárias experimentaram uma grande fase de expansão. Os preços dos imóveis se mantiveram elevados criando a ilusão de que os financiamentos e os investimentos ainda se estenderiam por um longo prazo.

Com o mercado aquecido, as instituições financeiras passaram a conceder inúmeros empréstimos, em muitos casos com pouquíssima rigidez, deixando de 
observar a margem financeira segura dos clientes. Acreditavam que, em caso de inadimplência, a venda dos imóveis supervalorizados seria capaz, não somente de cobrir os empréstimos, mas também oferecer alguma margem de lucro. Com base neste otimismo, inovações financeiras derivadas destas operações passaram a ser comercializadas.

Como os financiamentos imobiliários são empréstimos de longo prazo, a entidade proprietária dos títulos vendia-os antecipadamente, por um valor recuperável mais baixo com o intuito de obter saldo em caixa mais rápido e aumentar o volume de operações. Este era, no entanto, um falso pressuposto, os derivativos são instrumentos financeiros que diluem o risco do investimento, mas não o eliminam. Estes papéis foram se espalhando de instituição para instituição, tornando a cadeia de comercialização cada vez mais complexa, deixando os riscos, por seu turno, cada vez menos transparentes.

Bresser-Pereira (2008, p. 197) atribui à causa direta da crise esta “[...] concessão de empréstimos hipotecários, de forma irresponsável, para credores que não tinham capacidade de pagar ou que não a teriam a partir do momento em que a taxa de juros começasse a subir, como de fato aconteceu.".

Diante da impossibilidade de cumprir com as obrigações firmadas nos financiamentos dos imóveis, não tardou para que a bolha no setor imobiliário estourasse, uma vez que ficou evidente que as operações estavam sendo lastreadas por ativos podres. O nível de inadimplência aumentou de forma acelerada causando prejuízos bilionários em cascata, levando a falência inúmeras instituições financeiras e exigindo uma intervenção estatal sem precedentes no mercado financeiro americano. A bolha teve repercussão mundial, tendo sido caracterizada como a segunda maior possibilidade de risco sistêmico já experimentada pela economia global.

\subsection{Bolhas de Preços}

Ao observarmos o mercado acionário, é possível perceber que os preços dos ativos negociados se alteram inúmeras vezes diariamente. Isso se dá pelo reflexo das informações de cunho econômico e financeiro que influenciam as atividades de cada setor. Estas mudanças são consideradas normais quando seguem determinadas tendências do mercado ou refletem os novos acontecimentos.

No entanto, muitas vezes são observadas alterações expressivas nos preços dos ativos sem motivo razoável aparente, que perduram durante um extenso período. Tais alterações podem ser bastante preocupantes quando estes valores se afastam muito dos preços considerados justos dos ativos e se mantém em longo prazo. A observação deste comportamento pode ser utilizada com uma ferramenta de previsão de uma bolha em formação e uma posterior queda de preços. 
Para Martin et al. (2004) a constatação empírica mais direta de bolha especulativa ocorre quando se observa a supervalorização dos preços de determinado ativo por um longo período seguida da queda abrupta destes valores. Neste mesmo trabalho, Martin et al. (2004, p. 233) explicam detalhadamente a teoria do modelo original de bolha especulativa:

O modelo original de bolha especulativa racional surge com Blanchard (1979) e Blanchard e Watson (1982). De acordo com este modelo a bolha surge quando o preço de um ativo é função crescente e positiva da variação esperada do preço futuro. O pressuposto é que os agentes econômicos, sob a condição de formar as suas expectativas de preço de forma racional, não cometem erros de forma sistemática, e, portanto, a relação positiva entre preço atual e sua variação futura esperada implica em relação igualmente positiva entre o seu preço atual e sua variação observada. Assim, as expectativas dos agentes se "auto-realizam", fazendo com que a variação dos preços dirija o atual preço no sentido de sua expectativa, independentemente de seus fundamentos. Vale dizer que, por um determinado período de tempo, os agentes econômicos agem em função deste raciocínio ou crença e isto faz com que os preços subam, não importando a trajetória dos dividendos. Os agentes têm ciência sobre a possibilidade de ruptura da bolha, porém o retorno esperado justifica assumir tal risco. O que se observa, porém, é que esse desvio entre o preço observado e o seu valor intrínseco pode ser tão demasiado, de tal maneira que poder-se-ia falar em especulação. Daí porque se denominar este fenômeno de bolha especulativa racional.

Outra concepção estudada é que bolha especulativa é como um feedback da interpretação dos acontecimentos. Estando a essência da bolha desde o crescimento de preços, ao entusiasmo exacerbado dos investidores e até demanda crescente que espera posteriores aumentos de preços. Esta grande demanda por ativos é gerada pela expectativa de que os altos retornos passados influenciarão positivamente os retornos futuros. Entretanto, as bolhas não são infinitamente sustentáveis, os preços não podem crescer eternamente. O problema se dá no momento em que se torna impossível a manutenção do crescimento de preços, quando a demanda, apesar de grande, não possui mais tantos recursos disponíveis para manter o mercado aquecido e o feedback, que antes era positivo, é substituído pelo feedback negativo. Tão logo, a bolha estoura (SHILLER, 2001).

Caselani (2003, p. 26) afirma que "[...] uma bolha especulativa ocorre quando os preços dos ativos negociados em um dado mercado sofrem uma forte valorização ou desvalorização sem que tal movimento reflita, de forma razoável, o 'valor justo' desses ativos. Ou seja, as bolhas especulativas envolvem, em maior ou menor grau, um movimento artificial de preços." 
Segundo Shiller ${ }^{1}$ (2000 apud MEDEIROS; DAHER, 2008, p. 3) "[...] o comportamento humano que, muitas vezes, se distância do comportamento racional previsto pelas finanças clássicas, pode ser uma das razões que levam os mercados financeiros a apresentar a dinâmica de bolha.". Para o mesmo pesquisador, em muitos casos é este entusiasmo exagerado dos investidores que sustenta alta de preços e não o próprio valor real do ativo.

Como as bolhas envolvem um grande número de investidores e empresas, podem ocasionar uma reação em cadeia ou, o conhecido, efeito "manada". Investidores tentam se livrar dos títulos que de uma hora para outra perderam valor, a demanda estagnada não supre essa oferta eufórica e as empresas emitentes das ações sofrem brusca desvalorização, assim podendo ocasionar uma crise econômica generalizada.

Neste contexto Westerfield, Ross e Jaffe (2008, p. 291) opinam que "Talvez as crises de mercado de ações sejam evidências compatíveis com a teoria de bolhas especulativas. Ou seja, preços dos títulos às vezes variam enormemente em torno de seus valores corretos. Eventualmente, os preços retornam a seus níveis originais, causando grandes perdas para os investidores.".

Sornette $^{2}$ (2004 apud FERNANDES, 2008, p. 37) enumera cinco possíveis estágios de evolução de bolha de preços:

a) a bolha inicia com o aumento da produção e da venda em contrapartida com um crescimento suave de percepção positiva em relação ao mercado;

b) há o destaque de investimentos que propiciam melhores retornos, atraindo também investidores internacionais, consequentemente inflacionando os preços;

c) o destaque dos investimentos no item dois atrai também pequenos e médios investidores neste estágio, o que diminui as margens de ganho, que aumenta a demanda por ações mais rapidamente do que a taxa real de juros;

d) a reação do mercado se distancia da real situação da produção industrial e de serviços;

e) com os altíssimos preços o número de novos investidores cai e o mercado entra numa fase de instabilidade que é levada ao colapso.

Para finalizar a análise conceitual de bolha, é relevante exemplificar três tipos específicos de bolhas, citados por Nunes e Silva (2009, p. 2): "[...] as bolhas explosivas, as bolhas periódicas e as bolhas intrínsecas".

O primeiro tipo de bolha citado ocorre quando há um desequilíbrio, a longo prazo, entre o preço da ação e os valores de seus respectivos dividendos. O segundo tipo refere-se às bolhas que estouram periodicamente, aquelas que, quando

1 SHILLER, R. Exuberância irracional. São Paulo: Makron Books, 2000.

2 SORNETTE, D. Why stock markets crash: critical events in complex financial systems. Princenton University Press, 2004. 
seus preços ultrapassam o valor limite, sofrem uma brusca desvalorização, próxima a zero, mas retomam o crescimento lentamente até o alinhamento entre o preço da ação e seus dividendos no longo prazo. E o último tipo de bolha, difere-se dos outros dois tipos no que tange os fatores extrínsecos, visto que esta espécie de bolha surge simplesmente da reação do valor da ação em relação à variação dos dividendos (NUNES; SILVA, 2009, p. 2).

\subsection{Hipótese de Mercado Eficiente}

A Hipótese de Mercado Eficiente (HME), publicada por Eugene Fama em 1970, afirma que nos mercados eficientes de capitais, o preço dos ativos financeiros é o reflexo de todas as informações disponíveis. Por exemplo, um investidor antes de comprar determinada ação busca no mercado informações sobre a empresa emitente, procura saber se a mesma tem apresentado resultados positivos, e aquele que deseja vender a ação, toma a decisão quando percebe que as informações da empresa não estão tão favoráveis quanto poderiam.

Com isso, Westerfield, Ross e Jaffe (2008, p. 280), comentam que “[...] a consequência lógica do fato de que toda essa informação é oferecida, estudada, vendida e utilizada no esforço de obtenção de lucro com a negociação de ações é a geração de um mercado eficiente."

Outro ponto importante da HME é que, em um mercado eficiente, não é possível se beneficiar excessivamente ou obter ganhos em altíssima escala com o uso das informações disponíveis. Ou seja, os investidores não devem esperar taxas de retornos além do que as informações possam refletir e as empresas não devem esperar de seus títulos emitidos valores maiores que seu valor justo.

Medeiros e Daher (2008, p. 2), neste contexto, afirmam que "A teoria dos mercados eficientes não elimina a possibilidade de existirem agentes irracionais (ruídos), mas determina que os agentes racionais ajam de modo a eliminar o ruído."

Para alcançar a eficiência, Fama (1970) cita algumas condições necessárias: as informações devem estar disponíveis a todos, não devem existir custos de transação na negociação e todos os investidores devem possuir expectativas homogêneas.

O que foi exposto é baseado no pressuposto de que as informações influenciam imediatamente o mercado, no entanto, na prática, diferentes informações levam tempo diferente para influenciar o mercado, sendo assim, a HME propõe três formas de eficiência de mercado: forma fraca, forma semiforte e forma forte.

A forma fraca baseia-se apenas em informações de preços passados. Como este é o tipo de informação mais fácil de encontrar, diz-se que esta é a forma menos exigente de eficiência encontrada no mercado. A fraqueza desta forma se dá pelo fato de que apenas descobrir um comportamento padrão dos preços passa- 
dos proporcionasse retornos exagerados, todos os investidores teriam esse potencial e o fariam, fazendo, então, com que tais lucros desaparecessem.

A forma semiforte de eficiência baseia-se em toda a informação publicamente disponível, desde informações de fusões de empresas até séries históricas de preços de ações. Se o mercado for eficiente em termos semifortes, uma notícia de aumento de lucro de determinada empresa influenciará imediatamente o preço da ação, logo, o investidor possuidor da informação assim que decidir adquirir tal ação não se beneficiará da informação, pois o preço já estará elevado quando for comprá-la. Muitos acreditam que esta seja a forma mais próxima de como funcionam os mercados na prática.

E por fim, a forma forte baseia-se tanto nas informações publicamente disponíveis como as não públicas, em outras palavras, qualquer informação relacionada à ação, mesmo que de conhecimento de pouquíssimos investidores, em um mercado de eficiência forte, refletirá integralmente no preço da ação (WESTERFIELD; ROSS; JAFFE, 2008).

\subsection{Valor Fundamental da Ação}

Segundo Nunes e Silva (2009, p. 2) “[...] o valor fundamental de uma ação pode ser definido como a soma de todos os pagamentos esperados de dividendos, levando em conta uma determinada taxa de desconto." Sendo considerado indício de bolha qualquer desvio anormal e generalizado do preço em relação ao valor fundamental da ação.

Para Lucas Jr. ${ }^{3}$ (1978 apud FERNANDES, 2008, p. 39), o valor fundamental de uma ação é a soma de todos os fluxos de caixa futuros que o ativo produzir, sendo a distorção entre seu preço real e o preço fundamental indício da formação de bolhas especulativas.

De acordo com o modelo de Gordon, que será explicado detalhadamente em outra sessão, o valor fundamental de uma ação pode ser calculado baseado no valor presente do fluxo esperado de dividendos futuros.

E finalmente, para Lintz ${ }^{4}$ (2004 apud MEDEIROS; DAHER, 2008, p. 1), ao considerar aceita a teoria de eficiência dos mercados, a mudança aleatória nos preços das ações, a racionalidade dos mercados, a impossibilidade de obter retornos exorbitantes nas negociações do mercado e a ausência de arbitragem, pode-se auferir que os fatores em conjunto contrariam a concepção de que existe algo além do valor fundamental nos preços das ações.

3 LUCAS JR, R. E. Asset prices in an exchange economy. Econometrica, v. 46, n. 6, p. 1429-1445, nov. 1978.

4 LINTZ, A. C. Dinâmica de bolhas de preços e finanças comportamentais: um estudo aplicado ao mercado de cambio brasileiro. São Paulo: FEA/USP, 2004. Tese de Doutorado não publicada. 


\subsection{Dividendos}

As sociedades por ações têm sua propriedade dividida entre seus inúmeros acionistas, alguns majoritários outros minoritários. Quando um investidor aplica recursos em uma empresa, acredita que a soma das captações de recursos ajudarão a empresa a manter ou melhorar suas atividades e espera obter, em troca, um retorno positivo futuro. Logo, uma forma de a empresa remunerar seus acionistas e estimular o aporte de capital é por meio do pagamento de dividendos. Segundo Westerfield, Ross e Jaffe (2008, p. 306), "Os dividendos pagos aos acionistas representam um retorno sobre o capital fornecido direta ou indiretamente à sociedade pelos acionistas.".

O primeiro conceito que se aplicará nos desenvolvimentos dos cálculos deste artigo será o de dividend yield - taxa de retorno de uma ação em dividendos, que pode ser encontrado através da divisão entre o dividendo pago por ação de uma empresa e o preço desta mesma ação. Aparentemente, quanto maior o dividend yield, melhor será o resultado da empresa ou mais atraente será sua política de dividendos. No entanto, é importante ressaltar que, por se tratar de uma divisão, é necessária que haja uma análise detalhada dos valores. Um dividendo baixo dividido por uma cotação também baixa da ação pode resultar em um número aparentemente elevado, o que neste caso não significa ser vantajosa a política de pagamento de dividendos, podendo ser, ao contrário, a indicação de algum problema que a empresa esteja passando.

O segundo conceito de dividendo que será utilizado nesta pesquisa é o de dividendo estimado de cada ação. Este valor pode ser encontrado a partir da multiplicação entre o valor da ação em determinada data e do dividend yield do ano em questão. Demonstrando em valor quanto a ação cotada na data distribuiu de dividendo no respectivo momento.

\subsection{Modelo de Gordon}

O Modelo de Gordon pode ser utilizado para determinar o valor fundamental de uma ação. Este modelo pressupõe que o valor de uma ação é o valor presente da soma do dividendo do período futuro com o preço da ação neste mesmo período, ou em outras palavras, o valor presente de todos os dividendos futuros (WESTERFIELD; ROSS; JAFFE, 2008, p. 103).

Ou seja, se um investidor está disposto a pagar $\mathrm{P}_{0}$ por uma ação hoje e deseja mantê-la pelo prazo de um ano, pode-se calcular o preço desta ação da seguinte forma:

$$
P_{0}=\frac{\operatorname{Div}_{1}}{(1+r)}+\frac{P_{1}}{(1+r)}
$$

Onde: 
$\mathrm{P}_{0}=$ o preço da ação que o investidor está disposto a pagar hoje

$\operatorname{Div}_{1}=\mathrm{o}$ dividendo esperado ao final do período

$\mathrm{r}=\mathrm{a}$ taxa de desconto da ação

$\mathrm{P}_{1}=\mathrm{o}$ preço esperado da ação no final do período (o qual outro investidor estará disposto a pagar futuramente)

No entanto, o valor de $\mathrm{P}_{1}$ não é escolhido ao acaso, ele é determinado em função do dividendo futuro, resultando no preço que outro investidor estará disposto a pagar em um dado momento visando obter este dividendo futuramente. Portanto:

$$
P_{1}=\frac{\operatorname{Div}_{2}}{(1+r)}+\frac{P_{2}}{(1+r)}
$$

E assim será para cada valor novo da ação. Como citado anteriormente, o preço da ação é o valor presente de todos os dividendos futuros. Tal afirmação pode ser confirmada se $\mathrm{P}_{1}$ - que compõe a equação 1 - for substituído pela equação 2, tornando possível deduzir o valor de $\mathrm{P}_{0}$ da seguinte forma:

$P_{\downarrow} 0=[(\operatorname{Div})]_{\downarrow} 1 /((1+r))+[(\mathrm{Div})]{ }_{\downarrow} 2 /[(1+r)]{ }^{\uparrow} 2+[(\mathrm{Div})] \downarrow_{\downarrow} 3 /[(1+r)]^{\uparrow} 3+\ldots=\Sigma_{\downarrow}(t=1)^{\uparrow} \infty \vdots \vdots \vdots:[(\mathrm{Div})]{ }_{\downarrow} t /[(1+r)]^{\uparrow} t$

Onde:

$\mathrm{P}_{0}=\mathrm{o}$ valor presente de todos os dividendos futuros esperados

$\operatorname{Div}_{\mathrm{t}}=\mathrm{o}$ valor do dividendo que deverá ser pago no ano $\mathrm{t}$

$\mathrm{r}=\mathrm{a}$ taxa de desconto da ação.

Ao mencionar série de dividendos futuros, o modelo pode sugerir ser somente aplicável a investimentos de longo prazo. No entanto, mesmo nos casos em que o investidor queira liquidar seu investimento em um curto período, a utilização do modelo é válida, tendo em vista que ele precisará encontrar outro investidor disposto a comprar sua ação por um preço que dependerá dos dividendos a receber futuramente - após a data da compra (WESTERFIELD; ROSS; JAFFE, 2008).

O que foi explicado até então, trata-se de um modelo geral, que não leva em consideração as possíveis alterações que ocorrem ao longo do tempo. No entanto, na prática é necessário avaliar o padrão de comportamento dos dividendos. Este comportamento pode ser avaliado de três maneiras: crescimento nulo (dividendo constante), crescimento constante ou crescimento variável.

No caso de crescimento nulo, pode-se calcular o valor da ação da seguinte forma:

$$
\mathrm{P}_{0}=\frac{\operatorname{Div}_{1}}{(1+\mathrm{r})}+\frac{\operatorname{Div}_{2}}{(1+\mathrm{r})^{2}}+\ldots=\frac{\mathrm{Div}}{\mathrm{r}}
$$

Nesta situação $\operatorname{Div}_{1}=\operatorname{Div}_{2}=\cdots \operatorname{Div}_{t}$ Sabendo que perpetuidade é uma série em que se espera que a remuneração seja sempre a mesma, ou seja, constante, de 
acordo com Westerfield, Ross e Jaffe (2008, p. 104), a fórmula acima não passa de uma aplicação da perpetuidade.

No caso de crescimento constante, onde é considerado que os dividendos crescem a uma taxa g, o cálculo do valor da ação é feito a partir do valor presente de uma perpetuidade constante, como mostra a seguinte equação:

$P_{0}=\frac{\operatorname{Div}}{(1+r)}+\frac{\operatorname{Div}(1+g)}{(1+r)^{2}}+\frac{\operatorname{Div}(1+g)^{2}}{(1+r)^{3}}+\frac{\operatorname{Div}(1+g)^{3}}{(1+r)^{4}}+\ldots=\frac{\operatorname{Div}}{r-g}$

Onde:

$\mathrm{P}_{0}=\mathrm{o}$ valor da ação

$\mathrm{g}=\mathrm{a}$ taxa de crescimento dos dividendos

$\mathrm{r}=\mathrm{a}$ taxa de desconto

Div $=$ o dividendo por ação no final do primeiro período.

No caso de crescimento variável, a elaboração de apenas uma expressão algébrica que represente o modelo apresenta certo grau de complexidade, por esta razão, este caso deverá ser resolvido por etapas. Calcula-se primeiro o valor presente líquido dos dividendos a cada taxa de crescimento e em seguida adota-se o mesmo procedimento utilizado nas perpetuidades.

\section{Metodologia}

A metodologia de pesquisa é a base que norteia os estudos, possibilitando o pesquisador a coordenar o trabalho, desenvolver hipóteses, interpretar resultados e solucionar a problemática levantada. De acordo com Silva e Menezes 5 (2001 apud PADRÃO, 2009, p. 8), "As pesquisas podem ser classificadas conforme os seguintes pontos de vista: natureza; forma de abordagem do problema; objetivos e procedimentos técnicos.".

Desta forma, a metodologia utilizada para o desenvolvimento deste artigo foi a positivista, visto que foram observadas tendências e características das variáveis de uma amostra de empresas, analisando a existência ou não causalidade entre ambas e, por fim, estabelecendo conclusões sobre os dados.

\subsection{Seleção e Período Amostral}

A amostra estudada neste artigo compreende o universo das empresas do ramo da construção civil, que possuem ações próprias negociadas na bolsa de valores de São Paulo, BMËF Bovespa. Destas empresas foram consideradas duas variáveis: séries históricas de cotações diárias das ações e seus respectivos divi-

$5 \quad$ SILVA, Edna Lúcia da; MENEZES, Estera Muszkat. Metodologia da pesquisa e elaboração de dissertação. 3 ed. Rev. Atual. Florianópolis: Laboratório de Ensino à Distância da UFSC, 2001.

FERNANDES, B. V. R.; SILVEIRA, A. J. E.; LUSTOSA, P. R. B. Bolha de preços no mercado... 
dendos estimados. Este último foi estabelecido a partir dos dividend yield anuais apresentados pela empresa confrontados com os valores das ações.

O tempo amostral se estende a partir de janeiro de 1995 até final de dezembro de 2009. No entanto, vale ressaltar, que devido à insuficiência de dados, nenhuma das empresas apresentou valores para todos os anos analisados do tempo amostral. Esta escassez de dados pode ser atribuída ao fato de que o setor ainda está se consolidando no mercado acionário.

\subsection{Teste de Cointegração de Engle-Granger}

Entende-se por cointegração a relação de longo prazo entre duas variáveis. Em outras palavras, duas variáveis são consideradas co-integradas, se houver entre elas uma relação de equilíbrio no longo prazo. Desta forma, a aplicação do teste de cointegração de Engle-Granger procura evidenciar a existência ou não de cointegração entre as séries históricas das seguintes variáveis: valor da ação e dividendos estimados, ao longo do período estudado.

Antes de partir para a explicação do teste em questão, é necessário que fique claro o conceito de estacionariedade aplicado às séries de variáveis. Brooks (2002) define série estacionária como aquela que possui significado constante, que sofre variações constantes. Afirma que, para este tipo de série, mudanças ocorridas em um determinado período que influenciam o comportamento das variáveis, vão perdendo seus efeitos ao longo do tempo. O mesmo autor cita que, ao contrário, séries não estacionárias sofrem mudanças sempre, e que seus efeitos não, necessariamente, reduzirão com o passar do tempo.

O teste Engle-Granger é composto por três etapas distintas: primeiro aplicar o teste Dickey-Fuller aumentado nas duas séries de variáveis em questão, segundo rodar a regressão destas variáveis pelo método OLS - Mínimos Quadrados Ordinários e por último, testar a estacionariedade dos resíduos da regressão.

\subsubsection{Aplicação do teste Dickey-Fuller aumentado (ADF)}

A primeira etapa, que consiste na aplicação do teste de Dickey-Fuller aumentado (ADF) nas variáveis estudadas, delimita as duas hipóteses centrais do deste de cointegração com as seguintes premissas:

$\mathrm{H}(1)$ : As variáveis apresentam cointegração.

Para confirmar a possibilidade de cointegração entre as variáveis nesta etapa, as séries analisadas devem ser não estacionárias apresentando raiz unitária ser integrado de ordem um, I(1).

$\mathrm{H}(2)$ : As variáveis não apresentam cointegração.

Se alguma das duas séries for estacionária - não apresentar raiz unitária, ou seja, ser integrado de ordem zero, I(0) - não poderá haver cointegração entre as variáveis. 
O teste $\mathrm{ADF}$ é feito a partir das seguintes equações:

$$
\begin{aligned}
& \Delta \mathrm{X}_{\mathrm{t}}=\beta \mathrm{X}_{\mathrm{t}-1}+\sum \theta_{\mathrm{i}} \Delta \mathrm{X}_{\mathrm{t}-1}+\epsilon_{\mathrm{t}} \\
& \Delta \mathrm{Y}_{\mathrm{t}}=\gamma \mathrm{Y}_{\mathrm{t}-1}+\sum \varnothing_{\mathrm{i}} \Delta \mathrm{Y}_{\mathrm{t}-1}+\epsilon_{\mathrm{t}}
\end{aligned}
$$

Sendo a equação 6 referente à variável $X$ - preço da ação - e a equação 7 referente à variável $\mathrm{Y}$ - dividendo estimado. Onde, em ambas, t refere-se aos lags de X e Y.

No caso das séries serem adequadas à hipótese, ou seja, apresentarem I(1), o teste de significância (teste-t) dos coeficientes $\gamma$ e $\beta$ não deverá resultar em valores significativamente diferente de zero (FERNANDES, 2008). Se for confirmada a existência das premissas desta etapa, o teste segue para o segundo passo.

\subsubsection{Teste de estacionariedade dos resíduos da regressão linear}

A terceira etapa consiste na conclusão do teste de cointegração. Neste momento é avaliado se há a ocorrência da segunda premissa que condiciona a confirmação da hipótese H(1).

Enquanto é condição para cointegração que as duas séries de variáveis apresentem raiz unitária, neste momento surge outra premissa para $\mathrm{H}(1)$ : a série dos resíduos deverá ser estacionária - não apresenta raiz unitária, I(0). É possível encontrar o valor de $\hat{u}_{\mathrm{t}}$, isolando-o na equação encontrada a partir da regressão linear do segundo passo do teste Engle-Granger.

Então, esta segunda condição pode ser testada a partir da seguinte equação:

$$
\Delta \mathrm{u}_{\mathrm{t}}=\beta \mathrm{u}_{\mathrm{t}-1}+\varepsilon_{\mathrm{t}}
$$

Onde:

$\varepsilon_{\mathrm{t}}$ é o erro de projeção em $\mathrm{t}$.

Portanto, se os resíduos $-\mathrm{u}_{\mathrm{t}}$ - apresentarem raiz unitária, serão não estacionários, concluindo que as variáveis em questão não apresentam cointegração no período analisado. Desta maneira, com a rejeição da hipótese $\mathrm{H}(1)$, confirma-se a ocorrência da hipótese $\mathrm{H}(2)$.

\section{Análise de Resultados}

A alta expressiva dos preços dos imóveis em algumas capitais brasileiras nos últimos anos destacou a possibilidade de uma formação de bolha no setor imobiliário. Com o intuito de buscar fatores que corroborassem esta hipótese, o trabalho analisou o comportamento das ações e seus respectivos dividendos das empresas que atuam no setor da construção civil no Brasil. A existência de componentes de bolha neste ramo não afirma de imediato que há uma bolha nos preços dos imóveis, no entanto, é possível falar em uma interdependência dos mercados. 
As empresas de construção civil comercializam seus produtos e têm suas atividades operacionais voltadas para o setor imobiliário e, como uma forma alternativa, captam recursos no mercado acionário para financiar estas operações. Tendo então estas sociedades anônimas como um elo, fica evidente a interdependência dos mercados. Neste ponto também é possível contextualizar a Hipótese de Eficiência de Mercado anteriormente citada, se estas empresas apresentam bons resultados no setor imobiliário, estes serão refletidos de forma positiva nos preços de suas ações, ou seja, um mercado acaba influenciando o outro.

Desta forma o presente trabalho determinou como o foco de pesquisa a análise da relação entre o comportamento dos preços das ações com seus respectivos dividendos estimados ao longo do tempo. Para a realização do estudo foram utilizadas técnicas estatísticas e econométricas.

A análise baseou-se no setor imobiliário nacional, constituído pelas empresas de construção civil que têm suas ações negociadas junto à bolsa de valores de São Paulo, BMEF Bovespa, e o período pesquisado foi de 1995 a 2009. No total foram encontradas 27 empresas do ramo, entretanto, 8 delas foram excluídas da pesquisa por não apresentarem dados disponíveis suficientes para a análise.

Sobre a amostra selecionada para a pesquisa, é oportuno destacar que 31,5\% destas empresas foram listadas no Ranking das 50 Maiores Construtoras no Brasil, de 2009, elaborado pela Câmara Brasileira da Indústria da Construção (CBIC) instituição que representa politicamente o setor tanto em âmbito nacional quanto internacional e trata de questões ligadas à indústria da construção e ao mercado imobiliário. As construtoras são: Camargo Corrêa Desenvolvimento Imobiliário S.A. $\left(2^{\mathrm{a}}\right)$, Gafisa S.A. $\left(10^{\mathrm{a}}\right)$, MRV Engenharia e Participações S.A. $\left(19^{\mathrm{a}}\right)$, Tecnisa S.A. $\left(21^{\mathrm{a}}\right)$, Rossi Residencial S.A. $\left(27^{\mathrm{a}}\right)$ e Trisul S.A. $\left(34^{\mathrm{a}}\right)$. A Tabela 1 mostra separadamente o período estudado de cada empresa:

Tabela 1 - Período dos Dados Coletados das Empresas

\begin{tabular}{lc}
\hline Empresa & Período \\
\hline Abyara Planejamento Imobiliário S.A. & $2007-2008$ \\
Agra Empreendimentos Imobiliários S.A. & 2009 \\
Brookfield Incorporações S.A. & $2007-2009$ \\
Camargo Correa Desenv. Imobiliario S.A. & $2007-2009$ \\
Cr2 Empreendimentos Imobiliarios S.A. & $2007-2008$ \\
Cyrela Brazil Realty S.A. Empreend e Part & $2006-2009$ \\
Even Construtora e Incorporadora S.A. & $2008-2009$ \\
Ez Tec Empreend. e Participações S.A. & $2008-2009$ \\
Gafisas S.A. & $2007-2009$ \\
Helbor Empreendimentos S.A. & $2008-2009$ \\
JHSF Participações S.A. & $2008-2009$ \\
\hline
\end{tabular}

(continua) 
(continuação)

\begin{tabular}{lc}
\hline Klabin Segall S.A. & $2007-2008$ \\
MRV Engenharia e Participações S.A. & $2008-2009$ \\
PDG Realty S.A. Empreend e Participações & $2007-2009$ \\
Rodobens Negócios Imobiliários S.A. & $2007-2009$ \\
Rossi Residencial & $1998-2001 / 2003 / 2005-2009$ \\
Tecnisa S.A. & $2007-2009$ \\
Trisul S.A. & 2008 \\
\hline
\end{tabular}

Fonte: Elaborada pelos autores.

\subsection{Estatísticas Descritivas}

O objetivo da estatística descritiva envolve desde a organização até a descrição dos dados, sejam eles quantitativos ou qualitativos (MARTINS, 2006). E no intuito de elaborar uma análise mais detalhada dos dados, alguns métodos estatísticos foram realizados. Primeiramente foram calculadas medidas de tendência central e medidas de dispersão relativas aos preços das ações de cada empresa analisada: a média, o desvio-padrão e o coeficiente de variação de Pearson.

Medidas de tendência central oferecem o posicionamento da distribuição, enquanto medidas de dispersão são "[...] medidas estatísticas utilizadas para avaliar o grau de variabilidade, ou dispersão, dos valores em torno da média. Servem para medir a representatividade da média." (MARTINS, 2006, p. 52).

O coeficiente de variação de Pearson é uma medida de dispersão relativa, que pode ser calculada da seguinte forma:

$$
C V=\frac{D P}{\bar{x}} \times 100
$$

Onde:

$\mathrm{CV}=$ o coeficiente de variação

$\mathrm{DP}=\mathrm{o}$ desvio-padrão da amostra

$\bar{x}=$ a média da amostra

As regras empíricas para interpretação deste coeficiente de variação, segundo Martins (2006, p. 58), são:

$\mathrm{CV}<15 \%$ : baixa dispersão

$15 \% \leq \mathrm{CV}<30 \%$ : média dispersão

$30 \% \geq C V$ : alta dispersão

Em seguida, no intuito de avaliar o ganho de capital por ação de cada empresa, foram calculados os retornos médios anuais das ações que podem ser obtidos a partir da equação 7. "O ganho de capital é a variação do preço da ação dividida pelo preço inicial." (WESTERFIELD; ROSS; JAFFE, 2008, p. 191). 


$$
R_{a}=\frac{P_{t}-P_{t-1}}{P_{t-1}}
$$

Onde:

$\mathrm{R}_{\mathrm{a}}=\mathrm{o}$ retorno anual da ação

$\mathrm{P}_{\mathrm{t}}=$ a última cotação da ação no ano

$\mathrm{P}_{\mathrm{t}-1}=\mathrm{a}$ primeira cotação da ação no ano

\subsubsection{Resultados estatísticos da amostra}

A partir da aplicação dos procedimentos estatísticos demonstrados acima na amostra de dados da pesquisa, conclui-se que, de uma forma geral, as empresas não apresentam comportamentos uniformes. Já no início da análise observou-se que as médias dos preços das ações no período variam bastante de uma empresa para outra, mostrando valores entre 2,16 reais e 18,95 reais - em média.

Em seguida, ao avaliar os coeficientes de variação de Pearson, ficou evidente o alto nível de dispersão dos dados amostrais, das 19 empresas estudadas, 16 apresentam dispersão elevada e as 3 restantes apresentam dispersão média. Sendo relevante enfatizar que nenhuma empresa apresentou baixo nível de dispersão.

E por fim, foi constatada uma enorme discrepância nos resultados dos retornos médios anuais, deixando clara uma evolução desproporcional dos preços das ações. Tais retornos se distribuem em um intervalo surpreendente de $74 \%$ negativo a $177 \%$ positivo. A Tabela 2 mostra detalhadamente os resultados obtidos:

Tabela 2 - Estatísticas Descritivas da Amostra

\begin{tabular}{lcccccc}
\hline Empresa & Média & $\begin{array}{c}\text { Desvio } \\
\text { Padrão }\end{array}$ & Mediana & $\begin{array}{c}\text { Coefi- } \\
\text { ciente de } \\
\text { variação }\end{array}$ & $\begin{array}{c}\text { Retorno } \\
\text { Médio } \\
\text { anual }\end{array}$ & $\begin{array}{c}\text { Retor- } \\
\text { no do } \\
\text { período }\end{array}$ \\
\hline $\begin{array}{l}\text { Abyara Planejamento } \\
\text { Imobiliário S.A. }\end{array}$ & 17,04 & 8,67 & 18,56 & $51 \%$ & $-15 \%$ & $-29 \%$ \\
$\begin{array}{l}\text { Agra Empreendimen- } \\
\text { tos Imobiliários S.A. }\end{array}$ & 3,26 & 1,49 & 3,06 & $46 \%$ & $177 \%$ & $177 \%$ \\
$\begin{array}{l}\text { Brookfield Incorpora- } \\
\text { ções S.A. }\end{array}$ & 8,61 & 4,59 & 6,99 & $53 \%$ & $30 \%$ & $90 \%$ \\
$\begin{array}{l}\text { Camargo Correa De- } \\
\text { senv. Imobiliário S.A. }\end{array}$ & 7,55 & 3,90 & 7,90 & $52 \%$ & $6 \%$ & $17 \%$ \\
$\begin{array}{l}\text { Cr2 Empreendimentos } \\
\text { Imobiliários S.A. }\end{array}$ & 11,47 & 5,74 & 10,05 & $50 \%$ & $-48 \%$ & $-97 \%$ \\
\hline
\end{tabular}

(continua) 


\begin{tabular}{|c|c|c|c|c|c|c|}
\hline $\begin{array}{l}\text { Cyrela Brazil Realty } \\
\text { S.A. Empreend e Part. }\end{array}$ & 18,95 & 5,30 & 19,45 & $28 \%$ & $36 \%$ & $144 \%$ \\
\hline $\begin{array}{l}\text { Even Construtora e } \\
\text { Incorporadora S.A. }\end{array}$ & 6,23 & 3,50 & 5,77 & $56 \%$ & $60 \%$ & $120 \%$ \\
\hline $\begin{array}{l}\text { EZ Tec Empreend. e } \\
\text { Participações S.A. }\end{array}$ & 4,52 & 2,11 & 4,31 & $47 \%$ & $61 \%$ & $195 \%$ \\
\hline Gafisa S.A. & 12,28 & 3,71 & 12,32 & $30 \%$ & $27 \%$ & $81 \%$ \\
\hline $\begin{array}{l}\text { Helbor Empreendi- } \\
\text { mentos S.A. }\end{array}$ & 6,97 & 3,35 & 6,98 & $48 \%$ & $147 \%$ & $294 \%$ \\
\hline $\begin{array}{l}\text { JHSF Participações } \\
\text { S.A. }\end{array}$ & 3,77 & 2,10 & 3,41 & $56 \%$ & $39 \%$ & $79 \%$ \\
\hline $\begin{array}{l}\text { João Fortes Engenha- } \\
\text { ria S.A. }\end{array}$ & 2,16 & 2,87 & 0,73 & $133 \%$ & $68 \%$ & $679 \%$ \\
\hline Klabin Segall S.A. & 12,59 & 5,53 & 12,68 & $44 \%$ & $-55 \%$ & $-110 \%$ \\
\hline $\begin{array}{l}\text { MRV Engenharia e } \\
\text { Participações S.A. }\end{array}$ & 8,73 & 3,47 & 10,06 & $40 \%$ & $111 \%$ & $221 \%$ \\
\hline $\begin{array}{l}\text { PDG Realty S.A. Em- } \\
\text { preend e Participações } \\
\text { S.A. }\end{array}$ & 10,08 & 3,34 & 10,35 & $33 \%$ & $77 \%$ & $230 \%$ \\
\hline $\begin{array}{l}\text { Rodobens Negócios } \\
\text { Imobiliários S.A. }\end{array}$ & 17,62 & 4,93 & 18,68 & $28 \%$ & $22 \%$ & $67 \%$ \\
\hline Rossi Residencial S.A. & 7,13 & 7,57 & 3,92 & $106 \%$ & $165 \%$ & $1655 \%$ \\
\hline Tecnisa S.A. & 7,93 & 3,05 & 9,78 & $38 \%$ & $37 \%$ & $111 \%$ \\
\hline Trisul S.A. & 6,34 & 2,87 & 6,79 & $45 \%$ & $-74 \%$ & $-74 \%$ \\
\hline Retorno médio total & 9,12 & 4,11 & 9,04 & $52 \%$ & $46 \%$ & $203 \%$ \\
\hline
\end{tabular}

Fonte: Elaborada pelos autores.

\subsection{Resultados dos Testes de Cointegração}

O parecer metodológico apresentou de forma detalha como é avaliada a relação de longo prazo das séries de variáveis. A existência das premissas necessárias para cointegração confirma a hipótese $\mathrm{H}(1)$ - concluindo que as séries analisadas possuem cointegração ao longo do tempo. No entanto, o estudo mostrou que em $68 \%$ dos casos analisados os preços das ações e os dividendos estimados não apresentam as premissas para cointegração. A Tabela 3 mostra os resultados obtidos pelos testes, junto com as respectivas conclusões. 
Tabela 3 - Análise dos Teste de Co-Integração

\begin{tabular}{|c|c|c|c|c|}
\hline Empresa & Preço ação & $\begin{array}{l}\text { Dividendo } \\
\text { Estimado }\end{array}$ & Resíduos & Conclusão \\
\hline $\begin{array}{l}\text { Abyara Planejamento } \\
\text { Imobiliário S.A. }\end{array}$ & Raiz unitária & Raiz unitária & Raiz unitária & Não-Cointegração \\
\hline $\begin{array}{l}\text { Agra Empreendimentos } \\
\text { Imobiliários S.A. }\end{array}$ & Raiz unitária & Raiz unitária & Não possui & Cointegração \\
\hline $\begin{array}{l}\text { Brookfield Incorporações } \\
\text { S.A. }\end{array}$ & Raiz unitária & Raiz unitária & Não possui & Cointegração \\
\hline $\begin{array}{l}\text { Camargo Correa Desenv. } \\
\text { Imobiliário S.A. }\end{array}$ & Raiz unitária & Raiz unitária & Não possui & Cointegração \\
\hline $\begin{array}{l}\text { Cr2 Empreendimentos } \\
\text { Imobiliários S.A. }\end{array}$ & Não possui & Raiz unitária & Não possui & Não-Cointegração \\
\hline $\begin{array}{l}\text { Cyrela Brazil Realty S.A. } \\
\text { Empreend e Part. }\end{array}$ & Raiz unitária & Raiz unitária & Não possui & Cointegração \\
\hline $\begin{array}{l}\text { Even Construtora e Incor- } \\
\text { poradora S.A. }\end{array}$ & Raiz unitária & Raiz unitária & Raiz unitária & Não-Cointegração \\
\hline $\begin{array}{l}\text { EZ Tec Empreend. e Parti- } \\
\text { cipações S.A. }\end{array}$ & Raiz unitária & Raiz unitária & Não possui & Cointegração \\
\hline Gafisa S.A. & Raiz unitária & Raiz unitária & Raiz unitária & Não-Cointegração \\
\hline $\begin{array}{l}\text { Helbor Empreendimentos } \\
\text { S.A. }\end{array}$ & Raiz unitária & Raiz unitária & Raiz unitária & Não-Cointegração \\
\hline JHSF Participações S.A. & Raiz unitária & Raiz unitária & Raiz unitária & Não-Cointegração \\
\hline $\begin{array}{l}\text { João Fortes Engenharia } \\
\text { S.A. }\end{array}$ & Raiz unitária & Raiz unitária & Raiz unitária & Não-Cointegração \\
\hline Klabin Segall S.A. & Raiz unitária & Raiz unitária & Raiz unitária & Não-Cointegração \\
\hline $\begin{array}{l}\text { MRV Engenharia E Partici- } \\
\text { pações S.A. }\end{array}$ & Raiz unitária & Raiz unitária & Raiz unitária & Não-Cointegração \\
\hline $\begin{array}{l}\text { PDG Realty S.A. } \\
\text { Empreend e Participações } \\
\text { S.A. }\end{array}$ & Raiz unitária & Raiz unitária & Raiz unitária & Não-Cointegração \\
\hline $\begin{array}{l}\text { Rodobens Negócios Imo- } \\
\text { biliários S.A. }\end{array}$ & Raiz unitária & Raiz unitária & Raiz unitária & Não-Cointegração \\
\hline Rossi Residencial S.A. & Raiz unitária & Raiz unitária & Raiz unitária & Não-Cointegração \\
\hline Tecnisa S.A. & Raiz unitária & Raiz unitária & Raiz unitária & Não-Cointegração \\
\hline Trisul S.A. & Raiz unitária & Raiz unitária & Não possui & Cointegração \\
\hline \multicolumn{3}{|c|}{ Total de dados que não apresentam } & & $68 \%$ \\
\hline \multicolumn{4}{|c|}{ Total de dados que apresentam cointegração } & $32 \%$ \\
\hline
\end{tabular}

Fonte: Elaborada pelos autores.

\subsection{Análise Final dos Resultados}

Após os estudos desenvolvidos ficou evidente o comportamento não uniforme apresentado pelos preços das ações e seus respectivos dividendos estimados das empresas do setor em questão. 
Por esta razão é pertinente fazer a interpretação dos resultados obtidos separando as empresas por período estudado, para serem feitas algumas comparações - o termo "período" neste momento será equivalente à quantidade de anos em que as séries das variáveis se distribuem.

A análise iniciará pelo conjunto que engloba o maior número de empresas, as quais possuem dados referentes a um período de dois anos. Estas são: (1) Abyara Planejamento Imobiliário S.A., (2) CR2 Empreendimentos Imobiliários S.A., (3) Even Construtora e Incorporadora S.A., (4) Ez Tec Empreendimentos e Participações S.A., (5) Helbor Empreendimentos Imobiliários S.A., (6) JHSF participações S.A., (7) Klabin Segall S.A. e (8) Engenharia e Participações S.A..

Neste primeiro grupo apenas a empresa (4) apresentou cointegração entre as séries de variáveis, todavia, do ponto de vista estatístico, o coeficiente de variação de $47 \%$ indica uma alta dispersão dos dados, e seu retorno médio anual é bastante elevado - $61 \%$ - sendo complicado mantê-lo neste nível por um longo período.

Por outro lado, as sociedades anônimas (1), (2) e (7) além de não apresentarem cointegração entre os preços de suas ações e os respectivos dividendos estimados, mostraram retornos médios anuais negativos e um coeficiente de variação configurando também uma alta dispersão na amostra.

Dentro deste mesmo conjunto foi encontrada outra situação bastante diferente das anteriormente citadas, as empresas (5) e (8) apresentaram retornos médios anuais positivos maiores que cem por cento, deixando muito claro que manutenção destes ganhos de capital é bastante complicada. E por fim, as empresas (3) e (6) mostraram altos retorno médio anual e coeficiente de variação.

O segundo conjunto possui dados referentes a três anos e é composto pelas seguintes sociedades: (9) Brookfield Incorporações S.A., (10) Camargo Corrêa Desenvolvimento Imobiliário S.A., (11) Gafisa S.A., (12) PDG Realty S.A. Empreendimentos e Participações, (13) Rodobens Negócios Imobiliários S.A. e (14) Tcnisa S.A..

Neste segundo grupo apenas as empresas (9) e (10) apresentaram cointegração entre as séries de variáveis. Entretanto, ambas possuem um coeficiente de variação alto, configurando uma alta dispersão dos dados. A empresa (9) apresentou um retorno médio anual de $6 \%$, podendo ser considerado um tanto baixo se comparado com o rendimento da caderneta de poupança - um dos investimentos com menos risco do mercado financeiro - que varia entre $7 \%$ e $12 \%$.

Enquanto as sociedades (11) e (13) possuem retornos médios anuais e coeficiente de variação medianos, as empresas (12) e (14) apresentam tais índices em níveis altos, corroborando a inconstância dos dados.

A sociedade anônima Cyrela Brazil Realty S.A. Empreendimentos e Participações foi a única com dados amostrais distribuídos num período de quatro anos. 
A mesma apresentou cointegração entre os preços de suas ações e os respectivos dividendos estimados, um retorno médio anual um pouco elevado - 36\% - e média dispersão dos dados - coeficiente de variação de $28 \%$.

E por fim, as empresas João Fortes Engenharia S.A. e Rossi Residencial S.A. apresentam dados referentes a dez anos, estes dois exemplos possuem a característica "tempo" mais adequada da amostra. Entretanto, ainda neste caso a falta de uniformidade dos dados se mantém evidente. Nestes dois casos também não há cointegração ao longo do tempo entre as variáveis e ambas as empresas apresentam altíssimos níveis de dispersão dos preços das ações. E ainda, no caso da Rossi Residencial S.A., o retorno médio anual da ação apresentado é de 165\%.

Esta análise permitiu confirmar a ocorrência da problemática levantada. As variáveis das empresas estudadas não apresentam comportamento equilibrado dentro do período de tempo analisado, ao contrário, mostraram total instabilidade nos dados. Tais fatos configuram a existência de componentes de bolhas nas ações das empresas do setor.

\section{Considerações Finais}

A partir da observação de uma alta expressiva de preços dos imóveis em algumas importantes capitais do Brasil, foi levantada a hipótese de uma possível formação de bolha no mercado acionário das empresas que atuam no setor da construção civil do país. Esta interdependência entre os mercados pode ser encontrada pela seguinte relação: no marcado imobiliário as empresas de construção civil comercializam seus produtos e, como uma forma alternativa, captam recursos no marcado acionário para financiar estas atividades operacionais. Isto faz com que seja esperado um comportamento similar dos dois mercados. Entretanto, é válido ressaltar que o fato de existirem indícios de bolha no mercado acionário do setor em questão, não resulta na confirmação da existência de bolha nos preços dos imóveis.

Com o intuito de identificar indícios que pudessem confirmar a existência de componentes de bolha no mercado acionário do setor da construção civil, o presente trabalho buscou relacionar referências teóricas consagradas com resultados de testes estatísticos e econométricos aplicados.

É notório que o mercado acionário funciona como um termômetro do desempenho das atividades dos setores e agentes econômicos, uma vez que os valores dos ativos nele negociados variam de acordo com as alterações que as empresas sofrem. Sendo assim, o universo estudado neste trabalho considerou o setor imobiliário brasileiro, constituído pelas empresas de construção civil que têm suas ações negociadas junto à bolsa de valores de São Paulo, BMËF Bovespa. A relevância desta amostra é enfatizada por apresentar 31,5\% das empresas listadas no 
Ranking das 50 Maiores Construtoras no Brasil, de 2009, elaborado pela Câmara Brasileira da Indústria da Construção (CBIC).

O estudo foi realizado a partir da análise das cotações históricas das ações relacionando-as com seus respectivos dividendos estimados ao longo do período analisado. A partir de testes estatísticos foi avaliado o grau de dispersão dos dados da amostra e utilizando-se de testes econométricos, buscou confirmar a existência ou não de cointegração entre as duas variáveis citadas.

Por se tratar de uma amostra bastante homogênea, composta apenas por empresas do mesmo ramo com períodos de análise similares, dentro de condições consideradas normais era esperado que o desempenho destas empresas fosse um tanto estável. Entretanto foi encontrada uma altíssima irregularidade no comportamento dos dados, não sendo observada uma tendência na relação entre os preços das ações e os respectivos dividendos no espaço de tempo estudado.

Os resultados obtidos permitiram concluir que, do ponto de vista estatístico, a amostra não apresenta uma linha de crescimento uniforme nos preços de ações, mostrando uma faixa de variação significativa dos ativos de uma empresa para outra. Também foi constatado, que $89 \%$ das empresas apresentaram um alto coeficiente de variação na amostra, que variaram entre 33\% e 133\%, demonstrando que os dados da amostra configuram uma altíssima dispersão no período. Além disso, o estudo demonstrou que os retornos anuais esperados das ações não caracterizam uniformidade alguma, mostrando ao mesmo tempo empresas com retornos negativos e outras com retornos médios maiores que 150\% ao ano.

Do ponto de vista econométrico, a análise foi realizada através da aplicação do Teste de Cointegração Engle-Granger nas séries das variáveis - cotações diárias de ações e respectivos dividendos estimados - o qual busca confirmar a existência, de uma relação de longo prazo entre séries citadas. O teste revelou que $68 \%$ das empresas mostraram que suas variáveis não possuem cointegração nos dados ao longo do tempo.

É importante ressaltar neste ponto, que durante a realização do trabalho foram encontradas certas limitações. Na realização do teste de cointegração, por se caracterizar uma análise de longo prazo, teria sido ideal que a base de dados fosse composta em sua totalidade pelo período inicialmente determinado, 15 anos. No entanto, o setor da construção civil ainda está se consolidando no mercado acionário brasileiro, se tornando mais expressivo apenas nos últimos anos, por esta razão há certa escassez de dados. Todavia, tal limitação não reduz a relevância do trabalho, não se tratando de um viés colocado na pesquisa, sendo apenas uma falta de dados disponíveis.

Sendo assim, a interpretação do conjunto de testes realizados com as análises dos conteúdos teóricos, aponta para a existência de um componente de bolha na amostra estudada. A determinação da existência de fato de uma bolha especula- 
tiva se dá apenas no momento de sua explosão, quando são apresentadas graves consequências tanto para investidores quanto para a economia em geral. Entretanto, é possivel avaliar componentes e fatores que caracterizam este processo de formação, antes que o estouro aconteça. Sendo assim, a identificação e a evidenciação de fatores que antecipem o seu processo de formação é de grande valia para evitar futuros prejuízos.

Reside neste ponto a relevância do presente estudo. Os resultados obtidos apontam para a possibilidade de existência de uma bolha especulativa em formação no mercado acionário do setor imobiliário brasileiro, uma vez que o comportamento dos preços das ações das empresas de construção civil do país, conforme demonstrado no período analisado, apresentou as premissas que confirmam esta hipótese.

Por fim, considerando que a atuação das empresas de construção civil é dividida em dois mercados: o mercado imobiliário (onde seus produtos são negociados) e o mercado acionário (onde há captação de recursos para investir nas atividades operacionais), fica clara a interdependência dos dois mercados. E apesar de serem situações distintas, é possível que haja alguma relação entre a presença de indícios de bolha no mercado acionário das empresas analisadas com a alta observada dos preços dos imóveis no país.

Alguns dos métodos e teorias utilizados nesta pesquisa foram aplicados de forma similar em outros trabalhos como o de Fernandes (2008), o de Medeiros e Daher (2008) e o de Nunes e Silva (2009), que buscaram fatores que caracterizassem a formação de bolha no mercado acionário brasileiro como um todo. Os três confirmaram também a existência de indícios de formação de bolha no mercado.

Este trabalho teve como foco principal a análise do comportamento das séries históricas de dividendos e dos preços das ações do setor da construção civil. Sabendo que o ramo em questão ainda se encontra em fase de consolidação no mercado acionário, fica aqui registrada uma sugestão para que pesquisas futuras compararem o resultado desta pesquisa com o comportamento destas variáveis em setores já consolidados.

\section{Referências}

BMËF BOVESPA. Empresas listadas - setor: construção civil. Disponível em: < http://www. bmfbovespa.com.br/cias-listadas/empresas-listadas/BuscaEmpresaListada.aspx?segmento= Constru\%c3\%a7\%c3\%a3o+CivilEidioma=pt-br > . Acesso em: 25 mar. 2010.

BRESSER-PEREIRA, L. C. Dominação financeira e sua crise no quadro do capitalismo do conhecimento e do Estado Democrático Social. Estudos Avançados, São Paulo, v. 22, n. 64, p. 195-205, set./dez. 2008. Disponível em: < http://www.bresserpereira.org.br/papers/2008/08.26.Dominacao_financeira.EstudosAvancados.pdf>. Acesso em: 1 ago. 2010. 
BROOKS, C. Introductory econometrics for finance. Cambridge: C. Brooks, 2002.

CASELANI, C. N. A Irracionalidade das bolhas. RAE Executivo, São Paulo, v. 2, n. 3, ago./ out. 2003.

CÂMARA BRASILEIRA DA CONSTRUÇÃO CIVIL. Ranking das maiores construtoras do Brasil. Disponível em: <http://www.cbic.org.br>. Acesso em: 24 ago. 2010

COM DINHEIRO. Histórico de cotações. 2010. Disponível em: <www.comdinheiro.com.br>. Acesso em: 25 mar. 2010.

. Histórico de dividendos, jcp e dividend yield. 2010. Disponível em: <www.comdinheiro.com.br>. Acesso em: 25 mar. 2010.

DAHER, C. E.; MEDEIROS. O. R. Evidências de bolhas especulativas no mercado de ações brasileiro. Rio de Janeiro: EnANPAD, 2008.

FAMA, E. F. Efficient capital markets: a review of theory and empirical work. Journal of Finance, v. 25, n. 2, p. 383-417, 1970.

FERNANDES, B. V. R. Evidências de bolhas de preços no mercado acionário brasileiro. In: CONGRESSO USP DE CONTROLADORIA E CONTABILIDADE, 9., 2009, São Paulo. Anais... São Paulo: FEA/USP, 2009.

MARTIN, D. M. L. et al. Identificando bolhas especulativas racionais no IBOVESPA (PósPlano Real), a partir de regimes markovianos de conversão. Economia, Brasília, v. 5, n. 3, p. p. 219-252, jan./jun. 2004.

MARTINS, G. A. Estatística geral e aplicada. 3. ed. São Paulo: Atlas, 2006.

MARTINS, M. L. De especulação também se vive. Revista Leituras da História, n. 16, 2009. Disponível em: < http://leiturasdahistoria.uol.com.br/eslh/Edicoes/16/artigo123045-3.asp>. Acesso em: 3 maio 2010.

MAZZUCCHELLI, F. A crise em perspectiva: 1929 e 2008. Novos estudos - CEBRAP, São Paulo, n. 82, p. 57-66, nov. 2008. Disponível em: <http://www.scielo.br/scielo.php?script=sci arttextËpid $=$ S0101-33002008000300003EZlng $=$ enEZnrm =iso $>$. Acesso em: 4 ago. 2010.

MEDEIROS, Otávio Ribeiro de; DAHER, Cecílio Elias. Evidências de Bolhas Especulativas no Mercado de Ações Brasileiro.. In: ENCONTRO DA ANPAD, 32., 2008, Rio de Janeiro. Anais... Rio de Janeiro: ANPAD, 2008.

NUNES, M. S.; SILVA, S. Bolhas racionais no índice Bovespa. Rev. Bras. Econ., Rio de Janeiro, v. 63, n. 2, p. 119-134, jun. 2009. Disponível em: <http://www.scielo.br/scielo. php? script $=$ sci_arttextEpid $=$ S0034-71402009000200004EIng $=$ emĖnrm $=$ iso $>$. Acesso em: 20 jun. 2010.

PADRÃO, L. V. B. Operações de business combinations: um estudo aplicado ao caso da Telemar e Brasil Telecom. Brasília: UnB, 2009.

QUANTITATIVE MICRO SOFTWARE. E-Views 5 User's Guide. Irvine, CA: QMS, 2004.

ROBERTS, H. V. Statistical versus clinical prediction of the stock market. In: CONFERENCE OF SECURITIES PRICE ANALYSIS. Chicago, 1967. (Unpublished work).

ROSS, S. A. et al. Administração financeira. 2. ed. São Paulo: Atlas, 2008.

SHILLER, R. J. Bubbles, human judgment, and expert opinion. 2001. Disponível em: < http:// docs.google.com>. Acesso em: 14 abr. 2010. 
SORNETTE, D. Why stock markets crash: critical events in complex financial systems. Princeton: Princenton University Press, 2003.

WESTERFIELD, Randolph W.; ROSS, Stephen; JEFFREY, F. Jaffe. Administração Financeira. Tradução Antonio Zoratto Sanvicente. 2. ed. São Paulo: Atlas, 1995. 


\section{Apêndices}

Tabela 4 - Empresas de Construção Civil com ações na BMËF Bovespa

\begin{tabular}{|c|c|c|c|}
\hline & Razão Social & Nome de Pregão & Segmento \\
\hline & Abyara Planejamento Imobiliário S.A. & Abyara & \\
\hline & Agra Empreendimentos Imobiliários S.A. & Agra Ibcorp & \\
\hline \multirow[t]{2}{*}{$(*)$} & Agre Empreendimentos Imobiliários S.A. & Agre Emp Imo & \\
\hline & Brookfield Incorporações S.A. & Brookfield & NM \\
\hline \multirow[t]{2}{*}{$(*)$} & Brookfield São Paulo Empreend Imobiliários S.A. & Company & \\
\hline & Camargo Correa Desenv. Imobiliário S.A. & CC Des Imob & NM \\
\hline$(*)$ & Cimob Participações S.A. & Cimob Part & \\
\hline$(*)$ & Construtora Adolpho Lindenberg S.A. & Const A Lind & \\
\hline \multirow[t]{3}{*}{$(*)$} & Construtora Tenda S.A. & Tenda & \\
\hline & Cr2 Empreendimentos Imobiliários S.A. & $\mathrm{Cr} 2$ & NM \\
\hline & Cyrela Brazil Realty S.A. Empreend e Part. & Cyrela Realt & NM \\
\hline \multirow[t]{5}{*}{$(*)$} & Direcional Engenharia S.A. & Direcional & NM \\
\hline & Even Construtora e Incorporadora S.A. & Even & NM \\
\hline & EZ Tec Empreend. e Participações S.A. & Eztec & NM \\
\hline & Gafisa S.A. & Gafisa & NM \\
\hline & Helbor Empreendimentos S.A. & Helbor & NM \\
\hline \multirow[t]{8}{*}{$(*)$} & Inpar S.A. & Inpar S/A & NM \\
\hline & JHSF Participações S.A. & JHSF Part & NM \\
\hline & João Fortes Engenharia S.A. & Joao Fortes & \\
\hline & Klabin Segall S.A. & Klabinsegall & \\
\hline & MRV Engenharia e Participações S.A. & MRV & NM \\
\hline & PDG Realty S.A. Empreend e Participações S.A. & PDG Realt & NM \\
\hline & Rodobens Negócios Imobiliários S.A. & Rodobensimob & NM \\
\hline & Rossi Residencial S.A. & Rossi Resid & NM \\
\hline \multirow[t]{3}{*}{$(*)$} & Sergen Serviços Gerais de Eng S.A. & Sergen & \\
\hline & Tecnisa S.A. & Tecnisa & NM \\
\hline & Trisul S.A. & Trisul & NM \\
\hline
\end{tabular}

Fonte adaptada: www.bmfbovespa.com.br (Acesso: 30/03/2010).

${ }^{(*)}$ Estas empresas foram excluídas da pesquisa por falta de dados suficientes. 
Tabela 5 - Coeficientes das Regressões para os testes de cointegração

\begin{tabular}{|c|c|c|c|c|c|}
\hline Empresa & $\alpha$ & $\beta$ & $\mathbf{R}^{2}$ & $\begin{array}{l}\text { Erro pa- } \\
\text { drão } \alpha\end{array}$ & $\begin{array}{c}\text { Erro pa- } \\
\text { drão } \beta\end{array}$ \\
\hline $\begin{array}{l}\text { Abyara Planejamento Imobili- } \\
\text { ário S.A. }\end{array}$ & 16,75791 & 4,859807 & 0,000889 & 0,580875 & 7,366363 \\
\hline $\begin{array}{l}\text { Agra Empreendimentos Imo- } \\
\text { biliários S.A. }\end{array}$ & $-0,001661$ & 197,8455 & 1,000000 & 0,000152 & 0,008373 \\
\hline Brookfield Incorporações S.A. & 9,528714 & $-9,585604$ & 0,01994 & 0,290099 & 2,473738 \\
\hline $\begin{array}{l}\text { Camargo Correa Desenv. } \\
\text { Imobiliário S.A. }\end{array}$ & 9,450026 & -1118436 & 0,168283 & 0,206007 & 9,279342 \\
\hline $\begin{array}{l}\text { Cr2 Empreendimentos Imobi- } \\
\text { liários S.A. }\end{array}$ & 14,88012 & $-7,626739$ & 0,262385 & 0,393888 & 0,665689 \\
\hline $\begin{array}{l}\text { Cyrela Brazil Realty S.A. Em- } \\
\text { preend e Part. }\end{array}$ & 15,31824 & 19,68854 & 0,146927 & 0,319525 & 1,512371 \\
\hline $\begin{array}{l}\text { Even Construtora E Incorpo- } \\
\text { radora S.A. }\end{array}$ & 5,552666 & 8,614051 & 0,019793 & 0,265434 & 2,730155 \\
\hline $\begin{array}{l}\text { EZ Tec Empreend. e Participa- } \\
\text { ções S.A. }\end{array}$ & 2,210823 & 16,73528 & 0,653913 & 0,094045 & 0,54833 \\
\hline Gafisa S.A. & 10,37171 & 25,1664 & 0,060466 & 0,307349 & 3,65691 \\
\hline Helbor Empreendimentos S.A. & 5,631761 & 6,593116 & 0,204704 & 0,180416 & 0,588278 \\
\hline JHSF Participações S.A. & 4,513724 & $-6,057908$ & 0,105535 & 0,132561 & 0,794298 \\
\hline João Fortes Engenharia S.A. & $-0,498232$ & 63,58027 & 0,291897 & 0,154302 & 3,187804 \\
\hline Klabin Segall S.A. & 15,45373 & $-50,31135$ & 0,144546 & 0,389535 & 5,517955 \\
\hline $\begin{array}{l}\text { MRV Engenharia e Participa- } \\
\text { ções S.A. }\end{array}$ & 7,221719 & 18,50037 & 0,149484 & 0,216583 & 1,987475 \\
\hline $\begin{array}{l}\text { PDG Realty S.A. Empreend e } \\
\text { Participações S.A. }\end{array}$ & 7,321589 & 27,96827 & 0,25795 & 0,204337 & 1,766636 \\
\hline $\begin{array}{l}\text { Rodobens Negócios Imobiliá- } \\
\text { rios S.A. }\end{array}$ & 17,87827 & $-1,05247$ & 0,002356 & 0,271803 & 0,808307 \\
\hline Rossi Residencial S.A. & 2,816855 & 68,42123 & 0,449703 & 0,175848 & 1,80671 \\
\hline Tecnisa S.A. & 7,988629 & $-0,74772$ & 0,000331 & 0,160683 & 1,534 \\
\hline Trisul S.A. & 0,001002 & 27,42215 & 0,999999 & 0,000417 & 0,001645 \\
\hline
\end{tabular}

Fonte: Elaborada pelos autores. 
Tabela 6 - Segmentos de atuação das Empresas de Construção Civil

\begin{tabular}{|c|c|}
\hline Empresas & Alguns dos segmentos de atuação \\
\hline Abyara Planejamento Imobiliário S.A. & $\begin{array}{l}\text { Incorporação de imóveis residenciais e } \\
\text { comerciais }\end{array}$ \\
\hline Agra Empreendimentos Imobiliários S.A. & $\begin{array}{l}\text { Residencial, comercial, hotéis, loteamento } \\
\text { e lajes }\end{array}$ \\
\hline Brookfield Incorporações S.A. & $\begin{array}{l}\text { Projetos residenciais, comerciais, incorpo- } \\
\text { rações e participação em projeto habitacio- } \\
\text { nal (Minha casa minha vida) }\end{array}$ \\
\hline Camargo Correa Desenv. Imobiliário S.A. & $\begin{array}{l}\text { Incorporações residenciais e comerciais, } \\
\text { obras ferroviárias e de saneamento, } \\
\text { construção de usinas, metrôs, aeroportos, } \\
\text { instalações petrolíferas e oleodutos }\end{array}$ \\
\hline Cr2 Empreendimentos Imobiliários S.A. & Residencial, comercial e shopping centers \\
\hline Cyrela Brazil Realty S.A. Empreend e Part. & Imóveis residenciais \\
\hline Even Construtora e Incorporadora S.A. & Segmentos residencial, comercial e hotéis \\
\hline EZ Tec Empreend. e Participações S.A. & Incorporação de edifícios residenciais \\
\hline Gafisa S.A. & $\begin{array}{l}\text { Incorporação e construção de imóveis resi- } \\
\text { denciais no Segmento de Média, Média- } \\
\text { Alta e Alta Renda }\end{array}$ \\
\hline Helbor Empreendimentos S.A. & Segmentos residencial e comercial \\
\hline JHSF Participações S.A. & Segmento residencial \\
\hline João Fortes Engenharia S.A. & $\begin{array}{l}\text { Segmento residencial, comercial, empresa- } \\
\text { rial e hotéis }\end{array}$ \\
\hline Klabin Segall S.A. & Segmento residencial \\
\hline MRV Engenharia e Participações S.A. & $\begin{array}{l}\text { Construção e incorporação residencial e } \\
\text { comercial }\end{array}$ \\
\hline PDG Realty S.A. Empreend e Participações S.A. & $\begin{array}{l}\text { Construtora e incorporadora residencial } \\
\text { para diversas classes (segmento econômico } \\
\text { - foco principal) e loteamento residencial }\end{array}$ \\
\hline Rodobens Negócios Imobiliários S.A. & Residencial e incorporação imobiliária \\
\hline Rossi Residencial S.A. & $\begin{array}{l}\text { Construção e incorporação residencial e } \\
\text { comercial }\end{array}$ \\
\hline Tecnisa S.A. & $\begin{array}{l}\text { Construção e incorporação residencial, } \\
\text { comercial e hotéis }\end{array}$ \\
\hline Trisul S.A. & $\begin{array}{l}\text { Segmento residencial (foco econômico até } \\
\text { médio e alto padrões), empreendimentos } \\
\text { alinhados e comprometidos com o progra- } \\
\text { ma habitacional - Minha casa minha vida) }\end{array}$ \\
\hline
\end{tabular}

Fonte: Elaborada pelos autores.

Recebido em: 30/10/2010. Aceito em: 02/09/2011. 